rev.relac.int.estrateg.segur.5(2):13-38,2010

\title{
DE LA HEGEMONÍA BRITÁNICA A LA HEGEMONÍA ESTADOUNIDENSE UNA TRANSICIÓN ECONÓMICA EN ARGENTINA Y BRASIL, 1870-1930*
}

Oscar Granados Erazo**

\section{RESUMEN}

Argentina y Brasil se convirtieron a finales del siglo XIX en dos países que, basados en un modelo exportador, lograron vincularse rápidamente al sistema económico internacional de una forma más profunda, en comparación con lo que habían podido conseguir durante el periodo colonial. La hegemonía económica británica fue pieza fundamental en el proceso de ambos países, sin demeritar los avances alemanes, franceses y estadounidenses. Por otra parte, en el resto de Latinoamérica, Estados Unidos avanzaba rápida y fuertemente en el fortalecimiento de su hegemonía económica; en los casos de Argentina y Brasil esta situación fue un proceso lento y diferente, que generó una transición económica de la hegemonía británica a la estadounidense.

Documento final del proyecto de investigación «Imperialismo, finanzas y política exterior: El poder capitalista 1780-1914» haciendo referencia a la transición hegemónica en Suramérica.

** Director Gerente de Hisbruck Ltd. Investigador en The Rothschild Archive Forum. Investigador en la Universidad Externado de Colombia. Profesor-Investigador en la Maestría de Relaciones y Negocios Internacionales, Universidad Militar Nueva Granada, Bogotá, Colombia. oscar.granadoserazo@gmail.com 
Palabras clave: Brasil, Argentina, hegemonía económica, inversión extranjera, globalización, comercio exterior

\begin{abstract}
Argentina and Brazil at the end of the nineteenth century became two countries which, based on an exporting model, managed to link quickly to the international economic system, in a deeper way that they could have achieved during the colonial period. The economic British hegemony was a fundamental piece in this process for both countries, without disregarding the German, French, and American advances. On the other hand, in the rest of Latin America, the United States moved ahead rapidly in the strengthening of its economic domination; in Argentina and Brazil this was a slow and different process, that originated an economic transition from the British to the American hegemony.
\end{abstract}

Key Words: Brazil, Argentina, economic hegemony, foreign investment, globalization, foreign trade

\title{
INTRODUCCIÓN
}

Los procesos imperiales han diferido unos a otros; su evolución se ha gestado en diferentes momentos históricos, determinando sus características, avances, derrotas y caídas. Los últimos imperios, el británico y el estadounidense, los primeros imperios anglosajones y anglófonos (Ferguson, 2004, p.63), han mostrado cierta cercanía en sus características; sin embargo, es bastante llamativo el proceso de desvanecimiento del Imperio británico y el inmediato reemplazo del mismo por los Estados Unidos, pues esta transición se dio en un periodo de tiempo muy corto, en el que el contexto político y económico norteamericano se había definido principalmente durante el siglo XIX. Situación algo similar a lo experimentado por el Imperio Británico en el siglo XVIII, durante la expansión capitalista, comercial y marítima del Imperio Holandés, que le permitió su consolidación política y económica para lograr una posición hegemónica durante el siglo XIX.

Los instrumentos bajo los cuales los imperios, una vez establecidos, llevan a cabo los diversos procesos de expansión a otros territorios, por lo general son de carácter impositivo y colonizador. Los casos de los Imperios Británico y Estadounidense, durante los siglos XIX y XX en Suramérica, tienen unas características diferentes, a pesar del poder que se vivía con la salida del Imperio Español y el Imperio Portugués por los procesos de independencia de principios del siglo XIX. Aunque Estados Unidos en ese periodo aún no contaba con la fortaleza y capacidad económica, naval y política que tenía el Imperio Británico, sí tenía intenciones futuras de fijar su posición en el continente americano. En su mensaje anual ante el Congreso en 1823 el presi- 
dente James Monroe determinó, lo que un siglo después concretaría el Presidente Roosevelt en su política del Buen Vecino, tratando de aminorar las acciones estadounidenses de principios de siglo en la política interna de países vecinos como Cuba, Colombia, Haití, República Dominicana y Nicaragua.

El gran beneficiado de la retirada española y portuguesa de Suramérica fue el Imperio Británico que, manteniendo los lineamientos o parámetros de la Santa Alianza, la intención de establecerse en estos territorios y las palabras desafiantes de los estadounidenses, logró consolidar una estrategia de puertas abiertas con la que buscó enlazar su fortaleza económica con los avances políticos y económicos de los Estados nacientes, donde se podía aplicar con rigor el término de estado en el sentido europeo (Hobsbawn, 1987, p. 31).

Aunque los británicos pudieron beneficiarse y hacer un acompañamiento durante parte importante del siglo XIX en los negocios, empréstitos, nuevos proyectos y, en ocasiones, en decisiones políticas en la llamada periferia del Imperio, para la primera era de la globalización ya se empezaba a ver la incipiente influencia francesa, posteriormente alemana y, por último, estadounidense. El gran poder económico y político que reinó durante el siglo XIX fue el del Imperio Británico, que sería relevado por el Imperio Estadounidense entrado el siglo XX de una forma rápida y sencilla, de tal manera que este hecho se registró con poca notoriedad y trascendencia en el continente, pero que, en últimas, significó una reconfiguración de la hegemonía económica en tierras americanas.

Acciones como la guerra contra España, la llegada estadounidense a Cuba, el avance en Puerto Rico y República Dominicana, la construcción de un territorio a cualquier precio y la posterior influencia en la política y la democracia suramericana durante el siglo XX, muestran un imperio con unas estrategias y acciones diferentes a las del Imperio Británico, el cual, durante el siglo XIX, había tenido una estrategia enfocada hacia lo económico y al beneficio de los negocios financieros y productivos, y no hacia la penosa necesidad de intentar anexar territorios americanos en cualquier espacio y ante cualquier oportunidad. Ya en el momento en que Estados Unidos tiene la capacidad para continuar con la anexión de territorios como cualquiera de los imperios pasados, se iniciaría una nueva era imperial.

Suramérica sería entonces el lugar en el que los imperios desarrollarían los procesos productivos necesarios para alcanzar sus objetivos económicos, diferente a lo que sucedía en África y en Asia, donde la colonización y la imposición fue la estrategia de la carrera imperial europea de finales del siglo XIX, al punto que la fiebre del imperialismo se adueña de los gabinetes europeos progresivamente (Mommsen, 1969, p.137). Aunque los británicos y americanos estuvieron interactuando en todo Suramérica, la profundización de las relaciones financieras y productivas más importantes se dieron, para el caso británico, en Argentina y Brasil, principalmente, seguido de Chile y Perú. Estos espacios serían abordados tímidamente por los estadounidenses, hasta el momento en que se involucraron en toda Latinoamérica con acciones contundentes como la 
separación de Panamá del territorio colombiano, la agresividad de los procesos productivos de la United Fruit Company no sólo en Colombia, sino en gran parte de Centro América, la imposición económica y fiscal en algunos territorios bolivianos, el desplazamiento de los empresarios chilenos en la consolidación de los procesos productivos de su país y en otras acciones que demostraban la intención de establecer su poderío a cualquier precio en Suramérica y en todo el continente americano.

¿Cómo fue y cómo se hizo esa transición?, ¿cómo los estadounidenses relevaron a los ingleses su posición económica dominante? Son preguntas que habitualmente no se plantean sino que se responden con el simple proceso de asumir el cambio. El propósito de este documento es revisar cómo se configuraron los imperios británico y estadounidense en Argentina y Brasil, cómo se dio su participación en la estructuración económica y política de los nuevos Estados y cómo se gestó ese cambio hegemónico en la época más sobresaliente de las exportaciones y su vinculación a la economía mundial, punto de partida de los avances económicos e industriales del siglo XX. Y establecer si fue un cambio de prioridades y estrategia de los directores de las estructuras imperiales, o simplemente el ascenso de otro imperio que veía en Argentina y Brasil un lugar indicado para forjar su interés nacional y su intención hegemónica; factores que transformarían profundamente la estructura económica y política de Latinoamérica, así como los cimientos de las relaciones internacionales con las potencias mundiales durante el siglo XX.

El documento se divide en cuatro secciones; una primera donde se revisa la configuración y el avance temporal y espacial de los imperios británico y estadounidense, partiendo de un esquema teórico; en una segunda sección las características y elementos propios de Argentina y Brasil como un destino imperial; en una tercera sección se analizará la forma como se estructura ese cambio hegemónico y, finalmente, una sección de conclusiones.

\section{LA CONFIGURACIÓN IMPERIAL}

La configuración imperial británica y estadounidense se puede determinar a partir de los elementos propios de un imperialismo económico tradicional, donde esa configuración, más allá de un proceso de avance territorial y el costo que significa su gestión como lo hizo el mismo Imperio Británico en Asia y África en diferentes momentos de su hegemonía o, el imperio español y portugués durante los siglos XVI y XVII, fue un proceso más sencillo de imposición del capital económico y financiero, que condujo al establecimiento de ciertas estructuras como la participación de las casas comerciales, la impartición de créditos a los gobiernos y la instauración de compañías para la explotación y exploración de los recursos naturales.

Una estrategia cercana a la holandesa usada un siglo atrás, donde se tenía como estrategia un imperio altamente rentable y flexible de bases comerciales que se extendían a lo largo del océano Atlántico e Índico, fue la que desarrollaron en Suramérica, tanto los británicos como los 
estadounidenses, ante la imposibilidad de avanzar territorialmente como lo hacían en otros lugares, posiblemente como lo sucedido en algunos pequeños lugares del Caribe. La supremacía comercial holandesa se basó en una adhesión estricta a la lógica de poder capitalista y no a la lógica del poder territorialista (Arrighi, 1999, p. 240), esta última utilizada por los españoles y portugueses en Suramérica siglos atrás.

Determinando esa lógica de poder capitalista, es necesario contemplar un elemento primordial de la economía política en la configuración económica de los imperios y es el concepto de expansión material desarrollado por Carl Marx, que soporta los avances económicos de los imperios, sin ser una teoría que explique directamente al imperialismo, pero que es funcional en la medida en que plantea una explicación a los fenómenos políticos desde una perspectiva materialista y económica (Winslow, 1931, p. 715). Aunque existen diferentes planteamientos teóricos del imperialismo económico, la teoría de Carl Marx, y los ajustes que hacen Hobson, Braudel y Arrighi, para explicar las características del imperialismo con los ciclos sistémicos de acumulación, es la más indicada para comprender la estrategia que los imperios británico y estadounidense utilizaron en los casos de Argentina y Brasil, siendo similar a la utilizada por los holandeses a finales del siglo XVI hasta finalizar el siglo XVIII.

Al centrar la atención en las fuerzas materialistas o económicas como principales determinantes del cambio histórico, Marx revolucionó el pensamiento de las ciencias sociales, pues a partir de un esquema basado en la filosofía de la historia de Hegel y el método dialéctico, estableció a la materia, superando a la idea hegeliana, como motor de los conflictos; de esta manera, logró instaurar al materialismo dialéctico como método para comprender y explicar el cambio histórico.

Las fuerzas de producción, dinámicas y cambiantes, son la antítesis en la dialéctica marxista de las relaciones estáticas de producción. Esto quiere decir que al comienzo de cualquier periodo histórico existe armonía entre ambas, posteriormente, las fuerzas cambiantes de producción (la tecnología) no se ajustan a las instituciones de las relaciones de producción existentes y esto genera cambios, no al punto de la revolución social planteada por Marx, pero los suficientes para conducir al ajuste de nuevos esquemas relacionales dentro del proceso de construcción del Estado y nuevas estructuras económicas. Esos procesos van conduciendo a cambios en la forma de manejar las actividades de acumulación de capital, dadas por la dinámica de las fuerzas de producción. En este momento de la historia hay un nuevo estado armonioso entre las fuerzas y relaciones de producción, pero las fuerzas dinámicas y cambiantes de producción garantizan que surgirán nuevas contradicciones, sin establecer cuál será el momento, debido a que no son ciclos perfectos.

La búsqueda de beneficios del capitalista y su reacción a los cambios de las tasas de retorno explican en gran parte la dinámica del sistema. Según Marx, los capitalistas tienen un fuerte impulso a acumular capital y reaccionan al incremento de los salarios y al descenso de sus retornos, por lo que trasladan sus actividades productivas a los lugares en donde los salarios sean 
más reducidos, o buscan nuevas actividades, acciones que conducen a los empresarios y banqueros a presionar a los Estados para que inicien nuevos proyectos expansionistas, o para trasladar sus actividades donde el retorno del capital sea cada vez mayor y donde el pago de los costos reales sea bajo, logrando producir más bienes y servicios con la financiación de nuevas actividades productivas.

De esta forma, el capitalista de Marx entra en el mercado con dinero $(M)$, compra los factores de producción y procede a producir mercancías (C), consecutivamente intercambia estas mercancías por dinero en el mercado y su éxito estará en el rendimiento que obtiene $\left(M^{\prime}\right)$, que es la diferencia de dinero con la que comienza y la cantidad final. Una economía capitalista se representa por:

$$
M \rightarrow C \rightarrow M^{\prime}
$$

Donde: $M^{\prime}-M=\Delta M$ que es el rendimiento del capitalista. El enfoque de Marx para estudiar las fluctuaciones económicas consiste en examinar las reacciones del capitalista a la variación en su tasa de retorno, es decir, a la variación de $\frac{\Delta M}{M}$. Estas variaciones alteran la inversión, y la volatilidad que representa ese cambio es la principal causa de las crisis económicas. El descenso de los beneficios perjudica la acumulación de capital y la economía se encamina hacia la depresión; al ver que la actividad interna no mantiene la acumulación de capital se requiere buscar las actividades en mercados internacionales.

Marx pensaba que la acumulación de capital, las economías de escala, el crecimiento de los mercados de crédito y el predominio de la sociedad anónima en la organización de las empresas provocarían la concentración y la centralización del capital en manos de un número cada vez menor de personas. La competencia acabaría destruyéndose y la gran sociedad anónima asumiría el poder monopolístico. «Con la gran sociedad anónima vendría la separación de la propiedad y el control, así como una serie de consecuencias sociales negativas: una nueva aristocracia financiera, un nuevo tipo de parásitos en forma de promotores, especuladores y consejeros meramente nominales, todo un sistema de estafa y engaño por medio de malabarismos, agiotaje y especulación con acciones. Es producción privada sin el control de la propiedad privada» (Marx, 1926, p. 519).

Complementando la teoría ajustada de Carl Marx con la propuesta de J. A. Hobson, la cual determina que la expansión colonial de los países capitalistas se debe en gran parte a una salida del exceso de ahorro y el exceso de oferta de bienes generados en condiciones de pleno empleo (Hobson, 1902, p. 60), en esta medida se identifica que los dueños del capital, en su proceso de acumulación, fortalecían el avance del imperialismo de los Estados en aras de mantener su retorno, algo que fue propio del imperialismo británico y estadounidense en Suramérica y confirmado posteriormente por Lenin en su obra Imperialismo el máximo estado del capitalismo, aunque simplemente puede sustentarse sobre la profundización de los negocios internacionales, cuando estos no influyen en política. 
Esto significa que a partir de la expansión material (MC), la cual es una acumulación de capital, se genera la expansión financiera $\left(\mathrm{CM}^{\prime}\right)$, es decir, que en las fases de expansión material el capitalismo pone en movimiento una creciente masa de mercancías (incluida la fuerza de trabajo mercantilizada y los recursos naturales) y en las fases de expansión financiera una creciente masa de capital-dinero se libera de su forma de mercancía y la acumulación se realiza mediante procedimientos financieros. En su conjunto, las dos fases constituyen un ciclo sistemático de acumulación completo (MCM') (Arrighi, 1999, p. 19), el cual se acompaña de los procesos de financiación de actividades comerciales y productivas.

Al verificar la lógica de dominio territorialista $\left(\mathrm{TMT}^{\prime}\right)$ se identifica al poder con la extensión del territorio y la densidad de la población del mismo, y concibe la riqueza-capital como un medio o un subproducto de la prosecución de la expansión territorial. Una lógica de dominio capitalista $\left(\mathrm{MTM}^{\prime}\right)$, por su parte, identifica al poder con el grado de control sobre recursos escasos y considera las adquisiciones territoriales como medio y subproducto de la acumulación de capital. La lógica de dominio territorialista tiende a incrementar su poder a través de la expansión del tamaño de su contenedor; la lógica de dominio capitalista, por el contrario, tiende a aumentar su poder acumulando riqueza en el interior de un pequeño contenedor y a incrementar las dimensiones del mismo tan solo si ello se halla justificado por las exigencias de acumulación de capital (Arrighi, 1999, p.49).

Esta última lógica es la que configura un imperio capitalista, que no ve en el territorio el eje de su avance, sino que se convierte en un medio para incrementar su acumulación de capital, sin necesidad de una instauración de la propiedad por medio de acciones impositivas sino más bien negociadas, presentándose como un avance económico para el territorio, debido a la experiencia y capacidad económica, productiva y financiera con la que, por ejemplo, contaban los británicos y estadounidenses en cada uno de los momentos de su expansión.

A partir de estos elementos teóricos se determinan los procesos imperiales británico y estadounidense para Suramérica, aclarando que el accionar de los imperios británico y estadounidense en otros lugares fueron producto de una combinación de la lógica de poder territorialista con la lógica capitalista, al punto de trasladarse en ocasiones a la imposición política y militar, como lo fueron los casos de Jamaica, Bahamas, Honduras Británica o Guyana para los británicos; Puerto Rico, Cuba, Hawái o República Dominicana para los estadounidenses.

La configuración del Imperio Británico fue un proceso que se consolidó paulatinamente, pero que con la Independencia de los Estados Unidos avanzó más rápido de lo que muchos pensaban al perder una colonia de esas dimensiones, con una estrategia que extendió el principio de centralización (Nicholson, 1910, p. 158), el cual permitía cohesionar las decisiones en la City de Londres con los vehículos imperiales, los procesos productivos y la acumulación de capital de una forma simple y sencilla, estableciendo la naciente estructura exportadora como un poderoso motor de crecimiento del ingreso nacional (Cain y Hopkins, 1980, p. 472). El libre comercio 
al interior de sus dominios fue una pieza fundamental, desde los centros de producción en Inglaterra hasta el abastecimiento de materias primas y recursos desde Canadá, Australia, Suráfrica e India, permitió que el avance de la revolución industrial se diera más rápido y la acumulación de capital lograra consolidar nuevas actividades productivas, continuando con el fortalecimiento de su aparato imperial y su activo estratégico que lo haría amo de los mares por más de cien años, gracias a su capacidad y fuerza naval.

En el momento que necesitó interactuar con los mercados mundiales, inició la apertura de sus mercados e influenció para que los demás países hicieran lo mismo, con la premisa de encontrar en la Gran Bretaña un lugar para vender cualquier producto y abastecer sus cada vez más grandes necesidades. «Las Ilanuras de América del Norte y de Rusia son nuestros trigales; Chicago y Odessa, nuestros graneros; Canadá y el Báltico, nuestros bosques proveedores de madera; Australasia contiene nuestras granjas de corderos; y en Argentina y las praderas occidentales de América del Norte están nuestras manadas de bueyes; Perú nos envía su plata, y el oro de África del sur y de Australia fluye hacia Londres; los hindúes y los chinos cultivan té para nosotros, y nuestras plantaciones de café, azúcar y especias están en todas las Indias. España y Francia son nuestros viñedos y el Mediterráneo nuestra huerta de frutales; y nuestros campos de algodón, que durante mucho tiempo estuvieron en el sur de los Estados Unidos, se están extendiendo ahora por todas las regiones templadas de la Tierra» (Citado por Kennedy, 1987, p. 250).

Este estado de cosas se complementa con el ingreso a un periodo donde la guerra había dejado de ser el gasto público más importante. Después de finalizadas las guerras religiosas y la firma del Tratado de Westfalia, el Imperio Británico estuvo sumido en un número de guerras incalculable por más de 150 años, pero con la derrota de Napoleón en Waterloo se iniciaría una paz de más de cien años: Pax Britannica. El trasladar recursos de las actividades productivas, comerciales y bancarias a soportar la economía de guerra debilitaba los avances económicos, pues no permitía la consolidación de la acumulación de capital, tanto de los capitalistas como del Gobierno.

Al reducirse el impacto económico de la guerra, el Imperio Británico prestó poca atención a la consolidación de un ejército que satisficiere sus necesidades de seguridad nacional, al punto en que en diversas ocasiones podían estar en una posición vulnerable frente a las eventualidades; los británicos no solo mostraron cada vez menos entusiasmo por las intervenciones militares en Europa, que siempre serían caras y tal vez inmorales, sino que concluyeron que el equilibrio entre las grandes potencias continentales, que prevaleció generalmente durante los seis decenios siguientes a 1815, hacía innecesario cualquier compromiso en gran escala por parte de Gran Bretaña (Kennedy, 1987, p. 253). Así mismo, el Imperio Británico se fue desprendiendo de la responsabilidad central de salvaguardar la protección de las colonias que contaban con su propia estructura de Gobierno, a partir de una resolución de la Cámara de los Comunes en 1862 que determinaba la responsabilidad y el costo de su propia defensa militar (Nicholson, 1910, p. 170). 
Los Estados Unidos, por otra parte, habían dirigido su acción a la consolidación de un territorio mayor hacia el occidente, y este interés distrajo su atención durante una parte importante del siglo XIX, es así como es posible discernir que la estrategia estadounidense estaba cimentada en la creencia de que la configuración de un territorio más amplio era fundamental para avanzar dentro del sistema económico internacional y de esta manera también consolidarse políticamente como Nación, pues al interior de la misma se presentaban diversos fallos políticos que años más tarde desencadenarían la guerra de secesión.

Es importante mencionar que la tradición imperial estadounidense se consolidó a partir del mismo proceso de su Independencia en 1776, cuando aún el sistema político americano consistía en una confederación de grandes estados independientes y un débil gobierno central (McGuire y Ohsfeldt, 1986, p. 79), con discursos políticos que mostraban el interés de avanzar más allá de aquellos territorios que se habían independizado de la imposición y yugo imperial de los británicos y que, posteriormente, se transformarían en los textos constitucionales de 1787, mostrando los intereses imperiales de sus gobernantes. Desde George Washington, que hablaba de Estados Unidos como un imperio naciente, Thomas Jefferson, que mencionaba que su constitución era una pieza fundamental para ampliar un gran imperio, el imperio de la libertad, James Madison, que abocaba enérgicamente por ampliar la esfera de acción para crear una gran república, James Monroe, que rechazaba cualquier intervención extranjera en el continente americano, o los propósitos de desplazar «legalmente» a los indígenas por parte del presidente Andrew Jackson, son una pequeña muestra que en un periodo de casi cincuenta años, los presidentes de los Estados Unidos tenían presente la necesidad de conformar y consolidar un imperio que los fortaleciera en la esfera internacional. De esta forma, quizá sea posible afirmar que la influencia de los nuevos grupos económicos que avanzaban en la economía estadounidense fueron los artífices de la institucionalización del imperialismo estadounidense o de sus intereses económicos a través del proceso constitucional ${ }^{1}$.

A partir de ese momento, el avance territorial estadounidense se daría en dos formas: en primer lugar, se realiza el desplazamiento de los indígenas que no eran una fuerza relevante y tecnológicamente estaba demasiado atrasada como para presentar algo más que una resistencia ineficaz y esporádica a las hordas de los colonos blancos que abundaban en el oeste, atraídos por la perspectiva de tierras vírgenes (Ferguson, 2004, p. 88); y en segundo lugar, la compra de territorios occidentales, la cual se pudo lograr gracias al soporte de su naciente capacidad productiva, que respaldaría la emisión de títulos financieros que funcionaron como garantía de muchos de los empréstitos que se contrataron para esa ampliación territorial y el avance de su moneda como medio de pago y unidad monetaria instaurada en 1792.

1 Para revisar el análisis de los intereses económicos en la Constitución de los Estados Unidos. Ver Beard (1913) y McGuiare y Ohstfeldt (1984) con un enfoque cuantitativo. 
Así también, como en algún momento la ayuda militar y económica de Francia (1778), España (1779) y Holanda (1780) permitieron la consolidación de la independencia de las trece colonias británicas, el Imperio Británico a través de sus banqueros permitió el avance territorial de los estadounidenses gracias al apoyo de la Casa Bancaria Baring en la estructuración de la operación financiera para la compra del primer nuevo territorio en 1803: Luisiana. Sin embargo, la compra de territorios hacia el sur y occidente se aceleró con la fuerte barrera británica a la intención de la naciente nación de buscar tierras al norte por medio de la fuerza, en su intento por lograr disuadir el bloqueo comercial británico. El proceso de adquisición de tierras duraría más de sesenta años e implicaría una anexión territorial de más de 8 millones de kilómetros cuadrados, uniendo el Atlántico con el Pacífico a un costo financiero de más de setenta millones de dólares y con algunos enfrentamientos acompañados por la fuerza de las armas (Zevin, 1972, p. 325).

En Suramérica, el Imperio Británico veía a Brasil y Argentina, y en menor medida territorios como Chile, Uruguay y Perú, como lugares propicios para su abastecimiento comercial y el avance de sus negocios, de la misma manera que Estados Unidos años después de su consolidación política y económica con la finalización de la guerra de secesión y la posterior recuperación económica. Aunque Estados Unidos al finalizar el siglo XIX era parte de la carrera imperial desatada con la Conferencia de Berlín de 1885 y los británicos, franceses y holandeses habían avanzado territorialmente en varios lugares del continente americano, su mirada hacia Suramérica tendría una connotación de imperialismo económico y no de imperialismo colonial y territorial, haciendo una variación de la lógica de dominio capitalista, en la que la llegada a nuevos territorios era considerada como vehículo para aumentar el nivel de acumulación de capital, multiplicando el que se había generado años atrás en los procesos productivos y comerciales y generando una evolución en el nivel de acumulación financiera; aunque cabe resaltar, no fue un proceso homogéneo en toda Suramérica.

\section{SURAMÉRICA: ¿OTRO DESTINO IMPERIAL?}

¿Qué hizo que los británicos y los estadounidenses no usaran en Suramérica la estrategia que estaban desarrollando en otros lugares del mundo?, ¿cuáles fueron las condiciones para que Brasil y Argentina no tuvieran la misma suerte que algunos territorios en el mar Caribe, desde Cuba hasta Guyana?

En primer término, es importante establecer que tanto Argentina como Brasil tuvieron características diferentes que beneficiaron su comercio y su evolución económica durante las etapas previas a la independencia. Así mismo, los intereses británicos en América Latina y su definición a partir de su estrategia en el equilibrio europeo y la relevancia para España y Portugal de cada uno de los territorios respectivamente, aportaron en esa diferencia también relacionada con la dinámica interna de cada una de las futuras naciones. 
Durante la época colonial, tanto Argentina en el Virreinato del Río de la Plata y la evolución de las capitanías en Brasil se consolidaron procesos económicos relevantes tanto para el Imperio Español como para el Portugués. El Virreinato contaba con una actividad minera hacia el norte importante y una actividad de comercialización en la región de Buenos Aires, pero más allá de eso existía una abundante tierra fértil en las provincias del litoral que permitían un acceso rápido y sencillo a la cuenca del Río de la Plata (Salvatore y Newland, 2003, p. 20).

Brasil, a su vez, contaba con estructuras diferentes que fueron parte importante del comercio colonial en el momento en que el azúcar dejó de ser el producto principal y de mayor importancia en el territorio americano para los portugueses, y que se fortalecieron con el hallazgo de oro en la Capitanía de Minas Gerais, cambiando la perspectiva portuguesa en el territorio brasilero, considerado como colonia deficitaria a pesar de la gran cantidad de recursos que generaba la Capitanía de Bahía. De esta manera, Brasil se estableció como el lugar principal para llevar a cabo el comercio portugués, desplazando a la ciudad de Goa, en la India, gracias a la consolidación de Río de Janeiro como el primer puerto para la comercialización del oro de Minas Gerais. La llegada de los británicos a Brasil se da de la mano con la cercanía que tenía con el Imperio Portugués y la presión que ejerció sobre este, primero, con la ayuda brindada para la defensa portuguesa frente a los ataques franceses y, segundo, con la posterior imposición de la Independencia del pueblo brasilero.

Para el caso de Argentina, los procesos de inversión y consolidación económica no fueron tan rápidos como sucedió en Brasil, los procesos económicos soportados sobre la inversión extranjera que permitía obtener importantes recursos de lo que era el Virreinato de La Plata, solo se dieron hasta el momento en que el incremento en las inversiones británicas se tradujo en un incremento de las exportaciones de la región del Río de La Plata (Ferns, 1950, p. 206-207). Un proceso que empezó a mediados de la década de 1870 con lana, cueros y algunos alimentos conservados a través de procesos rudimentarios, para principios del siglo XX la oferta de productos se había ampliado con volúmenes importantes de productos como la lana, el trigo, los cueros, el maíz y la linaza, y antes del inicio de la Primera Guerra los alimentos constituían ya la mayor parte de las exportaciones argentinas, que se beneficiaban con los avances tecnológicos como la refrigeración para la carne, que pasaría a estar entre los cinco productos más importantes: trigo, maíz, lana, carne congelada, cueros y linaza. Para los años previos a la Crisis de 1929, más del 70\% de las exportaciones argentinas se concentraba en alimentos (Díaz-Alejandro, 1970, p. 5-18), de esta forma, se convertía en uno de los países con mayor exposición al comercio exterior y una alta capacidad de adaptación a las condiciones de los mercados internacionales.

Cada una de estas naciones contó con un centro económico y urbano que se convertiría en una ciudad con funciones agroadministrativas, en enclaves para la acometida de la tierra y de sus recursos y en vehículos para establecer un orden imperial (Morse, 1984, p. 36), lo que permitió posteriormente la consolidación de los procesos mercantiles hacia las metrópolis en la era colonial, en la evolución económica de la independencia y posteriormente en la vinculación de las 
nuevas naciones al comercio global, partiendo de estructuras coloniales como fueron el Consulado de Lima, en primera instancia, y posteriormente el consulado de Chile y Buenos Aires; esta última se constituiría en un espacio estratégico que le haría competencia a Lima, debido a que pudo consolidarse como el puerto que uniría el comercio interior con el comercio de ultramar, incluyendo el comercio con Brasil, y ser una nueva opción en el Atlántico Sur que compensaría los altos costos de acceder por Lima cuando se trataba de operaciones mercantiles con Europa.

En ciertas ocasiones las ciudades como Lima, Buenos Aires, Santiago, Río de Janeiro y la evolución de Sao Paulo como nuevo centro industrial, financiero y tecnológico, no lograban en su totalidad ser el vehículo eficaz para la completa difusión del capitalismo (Morse, 1984, p. 42), sino más bien un lugar que reproducía la metrópoli imperial en menor medida, para posteriormente convertirse en el lugar que afianzaba el cambio económico, a partir de los procesos de descentralización que realizaban los poderes imperiales para mantener el control de sus colonias y los avances que algunas poblaciones lograron como centros productivos, financieros, comerciales, exportadores y en ocasiones burocráticos.

La gran cantidad de recursos naturales que durante largos periodos había aportado Brasil a la economía mundial, lo convirtió en un importante centro económico, que se iría disminuyendo a partir de la aparición de otros países que podían facilitar recursos naturales de forma más competitiva y se ajustaban más a las necesidades y estructuras de consumo de las naciones desarrolladas, al punto de fortalecer sustancialmente la capacidad adquisitiva de algunos grupos poblaciones en Brasil, en especial la aristocracia terrateniente, y a la población argentina en general. Por otro lado, Argentina en los cincuenta años antes de 1914 fue testigo de una de las más altas tasas de crecimiento en el mundo por un periodo prolongado de tiempo (Díaz-Alejandro, 1970, p. 3), al punto de tener para 1895 un ingreso per cápita a la par de países como Alemania, Holanda y Bélgica y más alto que el de Austria, España, Italia, Suiza, Suecia y Noruega (Mulhall, 1896, p. 391). Esto se fue consolidando por la incorporación constante de Brasil y Argentina en el sistema económico internacional y no de forma intermitente, como sucedía con otros países de Latinoamérica. La influencia británica significó un apoyo importante en la consolidación económica brasilera y argentina, pero el elemento esencial fue esa incorporación a partir de la optimización de la capacidad productiva y exportadora.

Esta capacidad y el mejoramiento de las condiciones económicas de la población facilitaron también el fortalecimiento de los procesos migratorios, ya que en una proporción similar el avance económico que se veía en Argentina, y en menor medida en Brasil, eran análogos a los avances que se presentaban en Estados Unidos. Para la década de 1870 la tasa de migración en Argentina superaba la de países como Brasil, Canadá y Estados Unidos (Tabla 2.1), al punto de convertirse en el país con mayor flujo de migrantes europeos, en especial italianos, españoles, franceses, alemanes, entre otros (Díaz-Alejandro, 1970, p. 25), esto le permitió fortalecer la producción y la transferencia de conocimiento y tecnología, dándole la posibilidad de diversificar sus procesos productivos de una forma tan importante como lo que se presentaba en 
ese momento en Estados Unidos, generando una de las tasas más altas de exportación per cápita y en ocasiones superando el rendimiento promedio en el uso del suelo y las toneladas que se generaban por hectárea en los productos agrícolas hasta entrada la Segunda Guerra Mundial ${ }^{2}$.

Tabla 2.1

Tasas de Migración por década hacia América x 1000 media poblacional

\begin{tabular}{|l|c|c|c|c|c|c|}
\hline \multicolumn{1}{|c|}{ País } & $\mathbf{1 8 5 1 - 6 0}$ & $\mathbf{1 8 6 1 - 7 0}$ & $\mathbf{1 8 7 1 - 8 0}$ & $\mathbf{1 8 8 1 - 9 0}$ & $\mathbf{1 8 9 1 - 1 9 0 0}$ & $\mathbf{1 9 0 1 - 1 0}$ \\
\hline Argentina & 38.5 & 99.1 & 117.0 & 221.7 & 163.9 & 291.8 \\
\hline Brasil & - & - & 20.4 & 41.1 & 72.3 & 33.8 \\
\hline Canadá & 99.2 & 83.2 & 54.8 & 78.4 & 48.8 & 167.6 \\
\hline Estados Unidos & 92.8 & 64.9 & 54.6 & 85.8 & 53.0 & 102.0 \\
\hline
\end{tabular}

Fuente: Galiani y Gerchunoff (2003) p. 128.

En Brasil, la economía tuvo un avance importante cuando se inició el proceso de diversificación agrícola, ya que se había concentrado en la producción cafetera; y de esta forma, algunas zonas del país se convirtieron en nuevos centros agrícolas económicos, como los estados de Amazonas y Para, que se vieron fortalecidos por la producción de caucho y el aumento internacional del precio de este producto, que pasó de $£ 182$ por tonelada en 1870 a $£ 512$ por tonelada en 1911 , además de un aumento en la exportación que pasó de 6.591 toneladas en 1870 a 38.547 toneladas en 1911, estableciéndose en Brasil como el segundo producto de exportación por ingresos durante el tiempo que la oferta y los precios se mantuvieron altos. El café se mantenía como el producto más importante en la economía brasilera, pues en ciertos momentos de la época en cuestión, Brasil suministraba más de la mitad de todo el café vendido en el mercado internacional. (Dean, 2000, p. 342).

El ascenso y el descenso repentino también se vivió en otros productos agrícolas como la caña de azúcar, el cacao y el algodón, los cuales se convirtieron en importantes productos para el comercio brasilero con ultramar; por ejemplo, en los finales de la Colonia, Brasil proveía el 10\% del mercado mundial de algodón y los otros productos se podían abastecer a escala mundial fácilmente. Es decir, Brasil contaba con varios productos importantes en el comercio exterior, lo que la hacía ser una potencia agrícola regional y en algunos productos una potencia mundial; pero esa ventaja se fue perdiendo por los bajos costos en otros centros de producción mundial

2 Revisar el análisis comparativo gráfico que realiza Mundlak y Regúnaga (2003) p. 240 
y por el alto costo tributario que se vivió en aquella época, además de no contar con el capital para ampliar la frontera productiva, por esta razón, el atraer capital extranjero para nuevas actividades productivas se convertiría en algo vital para el crecimiento económico del país. Existe un elemento adicional que redujo los ingresos del exterior y fue la imposición en ocasiones de intereses económicos extranjeros en la política económica, como fue el caso de la devaluación forzosa impuesta por parte de la casa bancaria de los Rothschild en 1898 para otorgar un crédito que le permitiría estabilizar sus finanzas (Dean, 2000, p. 346).

Es importante identificar que los elementos políticos internos fueron pieza fundamental en la conexión con el sistema económico internacional, aunque en ocasiones se puede ver como un proceso de reacción o de acoplamiento ante los movimientos internacionales, los cuales jugaron un papel relevante en el avance económico de estas dos naciones, sin entrar a establecer si fueron acertados o no. Ejemplo de esto fue la Constitución de 1891 que le dio a la economía brasilera elementos para que los estados organizaran su propia estructura económica y su desarrollo; es así como algunos estados como Sao Paulo contrataron deuda por encima de lo que lo hacía el gobierno nacional e impusieron en muchas ocasiones los presidentes que estarían en el poder los siguientes cuatro años. Sao Paulo y Minas Gerais eran los estados más importantes, los cuales serían acompañados posteriormente por Río Grande do Sul; en un segundo nivel estaban Bahía, Río de Janeiro y Pernambuco, que servían como bases de poder para nominaciones presidenciales disidentes (Skidmore y Smith, 2001, p. 153). En el caso de Argentina, la reforma monetaria de 1899 acercó al país a un estabilidad financiera que se venía estructurando desde 1893, después del debacle financiero de 1890 y la cesación de pagos que estuvo a punto de llevar a la quiebra del Banco Barings, el mayor prestamista internacional del avance económico argentino. Ese puede ser el periodo más complejo para la economía argentina durante la época del auge exportador.

La política exportadora de Brasil no siempre fue exitosa, lo que en ocasiones trastornó sustancialmente el avance de un país con vocación exportadora natural, que pudo ser fuerte desde la misma época en que se instauró la República, pero que por la importante intervención de las oligarquías en búsqueda de proteccionismos al interior del país y los impuestos a las exportaciones, se condujo al estancamiento de la productividad y la competitividad en los mercados mundiales y en la apertura de nuevos mercados. Sin embargo, al interior del país la clientela se incrementó gracias al aumento de la influencia de la migración de colonos europeos, con nuevas necesidades y solicitudes en el mercado interno (De Azevedo, 1944, p. 57). Adicionalmente, el sistema mundial de comercio e inversión en el que se basaba la orientación exportadora de Brasil sufrió un tremendo revés con la Primera Guerra Mundial (Dean, 2000, p. 347), ya que no solamente vio reducido sus ingresos por exportación sino también por un sobrecosto en los bienes importados, lo que generó brotes inflacionarios y adicionalmente una disminución en los ingresos del gobierno, que casi lo lleva a su primera declaración de moratoria en octubre de 1914, solventada gracias a un crédito de salvamento obtenido en la ciudad de Londres.

Una explicación de esto fue lo que Brasil hizo para mantener los ingresos del café y fue la imposición de un proyecto llamado valorización o Convenio de Taubate (1906), donde los 
estados cafeteros compraban el café, lo almacenaban y esperaban que el precio compensara el costo; todo esto a través de la contratación de créditos externos con bancos europeos y estadounidenses, los cuales se verían beneficiados debido a que los créditos eran avalados por el gobierno federal. Este procedimiento tuvo éxito y benefició a todos los que se involucraron en este proyecto, al punto de que los bancos internacionales ampliaron su presencia en la actividad productiva brasileña. Algo similar ocurriría en la segunda valorización, sin embargo, la última ocasionó dificultades porque no se logró sostener el esquema y adicionalmente se tropezó con la depresión económica de 1929.

La adhesión de Brasil al grupo de los aliados en la Primera Guerra Mundial trajo consigo una caída de las inversiones de su segundo inversionista y prestamista de la época, Alemania, así como una serie de industrias que fueron confiscadas por la imposición de Inglaterra. A cambio recibiría una flota mercante alemana que se encontraba en puertos brasileños; sin embargo, el balance negativo lo trae la pérdida de varios recursos depositados en sus bancos y, lo más importante, el debilitamiento de un destino exportador y abastecedor de crédito. Argentina ya empezaba a mostrar su limitación a absorber los factores de producción del exterior y su economía y su política se tornaban cada vez más complejas con la llegada de la Primera Guerra Mundial, pues su economía se sustentaba principalmente sobre un modelo exportador y su mercado interno no absorbía la totalidad de la producción y, así mismo, no contaba con una industria que supliera los bienes de consumo importados. Argentina mostraba ya diferentes formas de democracia representativa, de desarrollo político y de reforma institucional que culminarían con un deterioro del sistema político que influiría posteriormente en el avance económico argentino y en la estabilidad social. Esto sumando a que su modelo exportador en tiempo de guerra no era igual de próspero que en tiempos de paz.

\section{EL RELEVO DE MANDO}

«Cuando existen varios imperios al mismo tiempo y cada uno pone en práctica su propia política imperialista de expansión industrial y territorial, se convierten inevitablemente en enemigos».

Hobson

El avance de Estados Unidos y Gran Bretaña y sus movimientos en Argentina y Brasil no representaron enfrentamientos, pero sí claramente una competencia por consolidar su presencia económica y lograr los objetivos de mantenerse o ser una potencia económica internacional. Algo que durante un siglo que culminaba con la Primera Guerra Mundial había consolidado a Gran Bretaña como la principal fuente de oferta de recursos para los países que buscaba financiación externa, y sus pretensiones como acreedor fueron sustancialmente mayores a las de cualquier otra nación hasta el inicio de la Segunda Guerra Mundial (Jenks, 1944, p. 68).

Estados Unidos, después de avanzar a cualquier precio en sus territorios aledaños, comenzó a consolidar sus inversiones paulatinamente, primero centrado en los lugares más cercanos a su 
región, después de haber arrebatado el último lugar de dominio del Imperio Español en su esfera de influencia: Cuba, la cual para 1930 era en Latinoamérica su lugar más importante de inversión, seguido de México y Chile, países que años antes eran el mayor destino de inversión estadounidense, pero que no superaban contundentemente la inversión británica (Tabla 3.1). Así mismo, después de la Gran Guerra, Estados Unidos utilizó su victoria para darle forma a la reconstrucción financiera internacional de acuerdo con sus intereses (Costigliola, 1977, p. 911), que claramente se relacionaban con su estrategia y posicionamiento dentro del sistema económico internacional.

El fortalecimiento estadounidense en los mercados cercanos de México y Cuba, claramente era parte de una estrategia económica que le permitía obtener recursos importantes, sin un traslado que implicara fortalecer su capacidad de carga marítima a partir de una alta inversión, que hasta ese momento era deficiente en comparación con las actividades navales de Gran Bretaña y Alemania. Sin embargo, el avance hacia el Oeste y el fortalecimiento económico de los territorios de California, implicaría la demanda por recursos y materias primas desde territorios con costas en el Pacífico. Una razón importante para el acercamiento y la demanda de recursos minerales de Perú y Chile y la comunicación hacia estas zonas de Latinoamérica, era que podían abastecer más rápidamente esta región de alto crecimiento económico y poblacional, sumado a un mejoramiento en los niveles de ingreso.

Tabla 3.1

Inversiones de Estados Unidos en América Latina, en millones de USD

\begin{tabular}{|c|c|c|c|c|}
\hline Ranking & País & 1897 & 1914 & 1930 \\
\hline 1 & México & $\$ 205,0$ & $\$ 853,5$ & $\$ 709,8$ \\
\hline 2 & Cuba & $\$ 50,0$ & $\$ 265,0$ & $\$ 1.066,6$ \\
\hline 3 & América Central (1) & $\$ 16,0$ & $\$ 95,5$ & $\$ 273,6$ \\
\hline 4 & Colombia & $\$ 8,2$ & $\$ 21,5$ & $\$ 301,7$ \\
\hline 5 & Caribe (2) & $\$ 7,0$ & $\$ 27,5$ & $\$ 115,7$ \\
\hline 6 & Perú & $\$ 6,0$ & $\$ 62,5$ & $\$ 200,1$ \\
\hline 7 & Venezuela & $\$ 3,8$ & $\$ 8,0$ & $\$ 247,2$ \\
\hline 8 & Chile & $\$ 2,0$ & $\$ 180,5$ & $\$ 700,9$ \\
\hline \multirow[t]{2}{*}{9} & Otros países de Sur América (3) & $\$ 8,0$ & $\$ 95,0$ & $\$ 1.586,3$ \\
\hline & Total & $\$ 320,0$ & $\$ 1.609,0$ & $\$ 5.201,9$ \\
\hline \multicolumn{5}{|c|}{$\begin{array}{l}\text { (1) Costa Rica, Guatemala, Honduras, Nicaragua y El Salvador. Panamá para el año de 1914, después de su indepen- } \\
\text { dencia de Colombia en } 1903 . \\
\text { (2) República Dominicana y Haití. } \\
\text { (3) Argentina, Brasil, Uruguay, Paraguay, Ecuador y Bolivia. }\end{array}$} \\
\hline
\end{tabular}

Fuente: Rippy (1949) p. 19-23 
La relación permanente con Chile y Perú, dada por la minería y la cercanía con sus centros de abastecimiento, fue generada por la alta demanda de una importante cantidad de recursos del avance californiano, aunque esto no sustenta la caída en las inversiones en México, en especial en la explotación de plata, que pasaría a ser para 1930 su segundo destino de inversiones después de Cuba. De la misma forma, Estados Unidos consolidaría su avance hacia América Central y, posteriormente, hacia el Caribe, en especial República Dominicana y Haití, con una estrategia definida y en compañía de los intereses empresariales en Guatemala, Honduras, Costa Rica y Colombia, influenciando el valor y las características de los factores de producción en varios lugares de estos países donde los empresarios tenían sus intereses (Lebergott, 1980, p. 239-245).

Aún en 1930 Argentina y Brasil sumaban 15.1\% de la inversión británica en el mundo (Tabla 3.2) y permanecían como los destinos más importantes en Suramérica. Gran Bretaña no se resistía a perder su influencia económica en la región, pero sus posesiones de ultramar empezaban a ser más rentables para sus actividades productivas, así como el cambio de prioridades comerciales que se trasladaban hacia los recursos energéticos de Oriente. Sin embargo, Argentina ya se había ganado un puesto importante en el mercado financiero londinense, al punto que entre 1886 y 1889 los títulos argentinos constituyeron aproximadamente el 20\% de los títulos extranjeros tranzados en este mercado (Marichal, 1984, p. 50) y se mantuvo hasta entrada la Primera Guerra Mundial.

Tabla 3.2

Mayores Receptores de Capital Británico

Participación Porcentual (\%)

\begin{tabular}{|c|l|c|c|c|}
\hline Ranking & \multicolumn{1}{|c|}{ País } & $\mathbf{1 8 6 5 - 1 9 1 4}$ & $\mathbf{1 9 3 0}$ & Variación \\
\hline 1 & Estados Unidos & $20.5 \%$ & $8.3 \%$ & $(-)$ \\
\hline 2 & Canadá & $10.1 \%$ & $13.2 \%$ & $(+)$ \\
\hline 3 & Argentina & $8.6 \%$ & $10.6 \%$ & $(+)$ \\
\hline 4 & Australia & $8.3 \%$ & $14.6 \%$ & $(+)$ \\
\hline 5 & India & $7.8 \%$ & $13.5 \%$ & $(+)$ \\
\hline 6 & África del Sur y otras regiones & $6.4 \%$ & $6.6 \%$ & $(+)$ \\
\hline 7 & Brasil & $4.2 \%$ & $4.5 \%$ & $(+)$ \\
\hline & Total & $\mathbf{8 6 . 6 \%}$ & $\mathbf{7 1 . 3 \%}$ & $(-)$ \\
\hline
\end{tabular}

Fuente: Kindersley (1933) p. 200; Stone (1999) p. 411 
Mientras las inversiones estadounidenses en Argentina para 1913-1914 no superaban los 40 millones de dólares, ya para 1929-1930 superaba los 800 millones de dólares, un crecimiento promedio anual de aproximadamente 133,6\%; para el caso brasileño la tasa de crecimiento promedio anual durante el periodo era de aproximadamente el $118 \%$.

La relación de inversión estadounidense y británica en estos países para 1913 era de 2.15\% para Argentina, y Brasil 4.30\%, es decir, que por cada dólar de inversión británica, Estados Unidos invertía 2.15 centavos y 4.30 centavos; para el año 1929 esta relación pasaba a 2,90 para Argentina y de 33,70 para Brasil, mientras que el promedio para Suramérica, excluyendo a estos dos países, era de la siguiente manera: por cada dólar invertido por los británicos, Estados Unidos invertía 1,30. Bajo los parámetros de la inversión extranjera, Gran Bretaña se mantenía como el mayor inversionista hasta 1930, a pesar del avance de los Estados Unidos en la región y de superar en varios países a los británicos, como es el caso de Colombia, Bolivia, Ecuador, Chile y Perú (Winkler, 1929, p. 95; Cardoso y Helwege, 1992, p. 49).

\section{Gráfica 3.1}

Inversiones de Gran Bretaña en Argentina y Brasil, 1875-1930, en millones de GBP

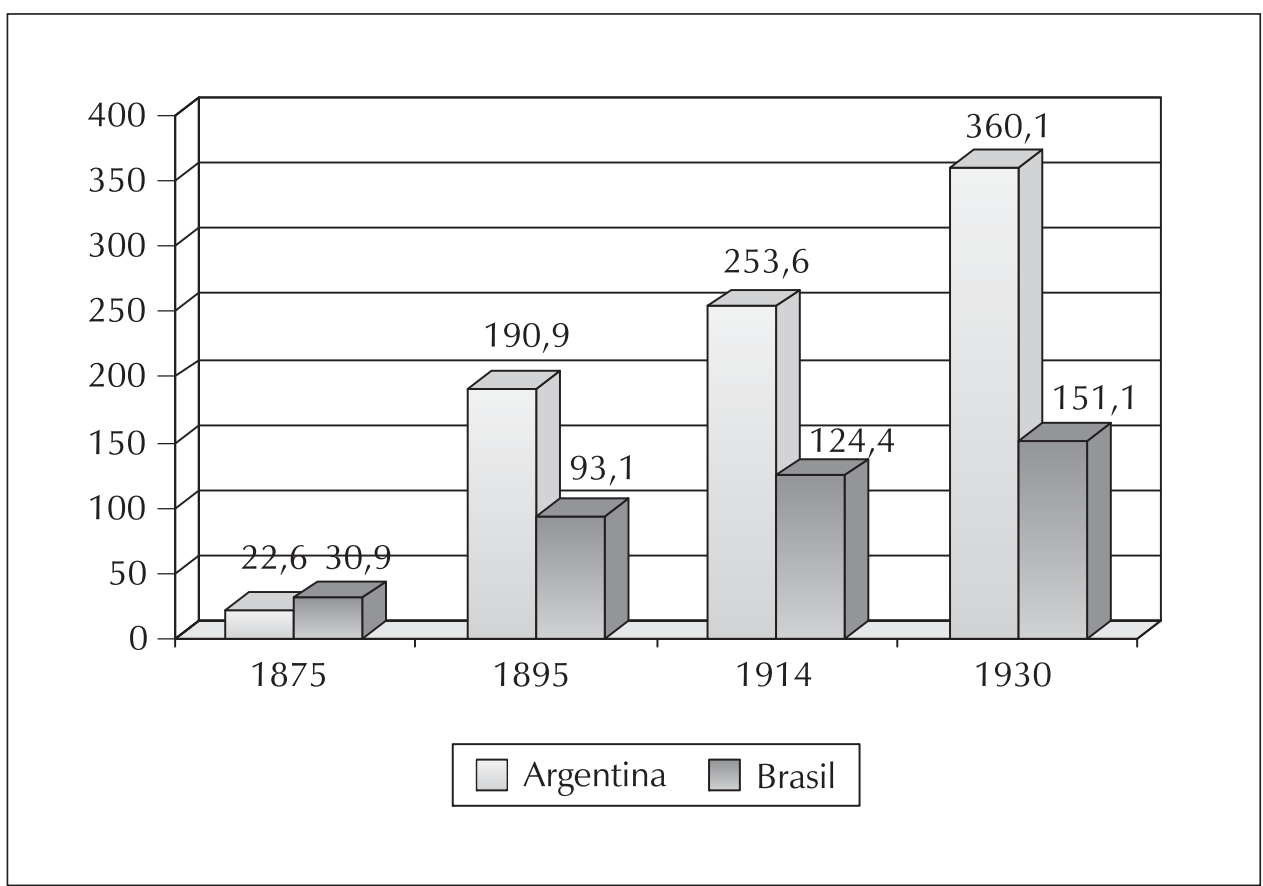

Fuente: Stone (1977) p. 695; Kindersley (1933) p. 200 
Gráfica 3.2

Inversiones de Estados Unidos en Argentina y Brasil, 1895-1930, en millones de USD

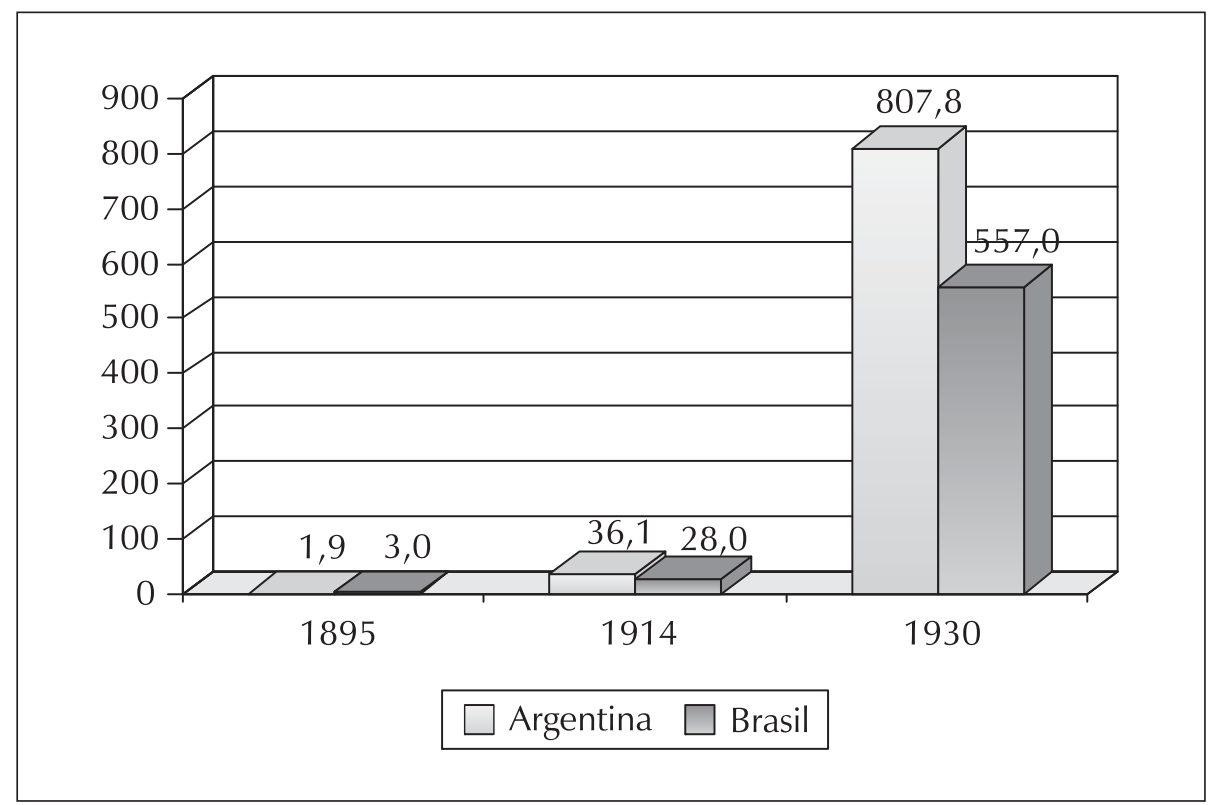

Fuente: Rippy (1949) p. 19-23

La inversión británica hacia Latinoamérica estaba concentrada en aquellos países que podían facilitar de una forma sostenida la demanda europea de recursos, pero igualmente para el caso argentino y en menor medida el caso brasilero, porque les permitía fortalecer una capacidad industrial a través de los procesos de inversión que daban una transferencia de tecnología importante. La principal influencia británica en Argentina fue la introducción de una compleja capacidad de gestión, innovaciones tecnológicas e ingeniería (Street, 1982, p. 547-548), que permitieron ciertos avances relevantes en la producción agrícola y ganadera, así como el fortalecimiento de los mercados externos para los productos como carne, cereales y café.

La intención de mantenerse como una potencia económica global hacía que las inversiones británicas se incrementaran cada vez más, pero serían los aspectos políticos que ya no se podían controlar, como en épocas anteriores, los causantes de la reducción de su participación, sumado al deterioro económico generado por la Segunda Guerra Mundial.

El crecimiento de las exportaciones presentaba un avance más activo en Argentina que en Brasil, por la posibilidad de diversificar constantemente su oferta de productos (Tabla 3.3) y por negociar aquellos teniendo en cuenta las condiciones y necesidades del sistema internacional: paz o guerra; Brasil, por su parte, al tener como primer producto el café, que en tiempos de guerra era 
un bien secundario, era relegado por Argentina y su producción de bienes de primera necesidad como la carne, el maíz o el trigo.

Tabla 3.3

Crecimiento de la Exportaciones 1870-1912 Promedio Anual (\%)

\begin{tabular}{|l|c|c|}
\hline \multicolumn{1}{|c|}{ País/Región } & $\mathbf{1 8 7 0 - 1 8 9 0}$ & $\mathbf{1 8 9 0 - 1 9 1 2}$ \\
\hline Argentina & 6.7 & 6.7 \\
\hline Brasil & 2.5 & 4.3 \\
\hline América Latina & 2.7 & 4.5 \\
\hline
\end{tabular}

Fuente: Bulmer-Thomas (2003) p. 64

Sin embargo, el papel británico en las exportaciones argentina y brasilera se redujo rápidamente por el deterioro del mercado interno causado por las dos guerras mundiales, pero que en ningún momento fue un proceso lento como habitualmente sucede en las transiciones económicas. Para 1913 de los 510,3 millones de dólares que exportaba Argentina, el 49.4\% se destinaba a los países de Centro, teniendo Gran Bretaña el 24.9\%, Alemania el 12.0\%, Francia el 7.8\% y Estados Unidos el 4.7\%; y Brasil, con unas exportaciones de 315,7 millones, el 71.5\% se concentraba en estos países, siendo Estados Unidos su mayor comprador con un 32.2\%, Alemania 14.0\%, Gran Bretaña 13,1\% y Francia 12.2\% (Bulmer-Thomas, 2003, p. 74). La mayor manifestación de la concentración de las exportaciones brasileras de café es visible cuando Estados Unidos se convierte en su mercado principal, gracias a sus tasas altas de crecimiento poblacional (Tabla 3.4).

El comercio con Europa, en especial con Gran Bretaña, crecía en menor medida en comparación con lo que sucedía con el mercado de los Estados Unidos, el cual había avanzado de forma importante no solo por el crecimiento de su población, sino por el incremento de su ingreso per cápita, que casi igualaba al de Gran Bretaña. Entre 1913 y 1929, previo a la Crisis, las exportaciones hacia Estados Unidos crecían 110.6\% y las importaciones desde Estados Unidos 161.2\%, mientras que para el caso británico era respectivamente de $45.5 \%$ y 34.5\% (Cardoso y Brignoli, 1979, p. 130-133). Sin embargo, para mediados de la década de 1920, en su orden, Argentina, Italia, Holanda, Estados Unidos y Alemania eran los destinos más importantes de las exportaciones brasileras y ya el nivel de importaciones se soportaba sobre los Estados Unidos y Gran Bretaña principalmente (Abreu, 2005, p. 18-20).

A pesar de la diversificación del proceso exportador y el crecimiento rápido hacia los Estados Unidos, el transporte y el almacenamiento de bienes para los mercados estadounidenses y europeos, desde los principales puertos de Suramérica, seguía en manos de los británicos: el Puerto de Santos en un 43.9\%, Río de Janeiro en un 46.3\%, Montevideo en un 53.6\% y Buenos Aires 
en un 56.2\%, para el año de 1912 (Albion, 1951, p. 373). Es así como para 1918 el volumen de exportaciones de los Estados Unidos era transportado sólo en un 18.9\% por buques de bandera estadounidense y las importaciones 35.9\%, mientras en 1914 el valor era de $8.4 \%$ y $11.9 \%$ respectivamente (Bullock, Williams y Tucker, 1919, p. 249). Algo similar ocurría con el negocio del transporte ferroviario, de donde los 31.859 kilómetros en Argentina, y los 24.737 en Brasil para 1913 (Bulmer-Thomas, 2003, p. 105) estaban en manos británicas en un porcentaje superior al 70\%, y quince años después bordearía el 60\% para el caso argentino (Wright, 1967, p. 63), y en un porcentaje superior al 50\% en Brasil. Este último soportado sobre un importante régimen de subsidios que buscaba consolidar un retorno para los inversionistas, pero también un retorno social importante, que se tradujo en un incremento en el nivel del endeudamiento del gobierno federal (Summerhill, 1998, p. 552-554).

Aunque Estados Unidos ingresaba fuertemente a Latinoamérica en diferentes actividades económicas, industriales y financieras, en los casos de Brasil y Argentina se mantuvo como mayor socio capitalista Gran Bretaña y como principal socio comercial Estados Unidos, situación que solo cambiaría en Argentina con la llegada de la Segunda Guerra Mundial; no obstante, logra hacerse efectivo hasta 1949, cuando la inversión privada de largo plazo de los Estados Unidos es de 447 millones de dólares contra 338 de Gran Bretaña; sin embargo, se debe tener en cuenta que era una situación que se presentaba en el ocaso de la inversión extranjera, en donde la inversión en capital fijo argentino era soportado por capital extranjero en un porcentaje no mayor al 5\%, teniendo presente que para 1913 bordeaba el 48\% (Lanciotti y Lluch, 2009, p. 41-42).

Tabla 3.4

\section{Comercio Exterior con los Estados Unidos 1913-1929 (\%)}

\begin{tabular}{|l|c|c|c|c|c|c|}
\hline \multirow{2}{*}{ País } & \multicolumn{3}{|c|}{ Exportaciones hacia Estados Unidos } & \multicolumn{3}{c|}{ Importaciones desde Estados Unidos } \\
\cline { 2 - 7 } & $\mathbf{1 9 1 3}$ & $\mathbf{1 9 1 8}$ & $\mathbf{1 9 2 9}$ & $\mathbf{1 9 1 3}$ & $\mathbf{1 9 1 8}$ & $\mathbf{1 9 2 9}$ \\
\hline Argentina & 4.7 & 29.3 & 8.3 & 14.7 & 21.6 & 23.2 \\
\hline Brasil & 32.2 & 34.0 & 45.5 & 15.7 & 22.7 & 26.7 \\
\hline América Latina & 29.7 & 45.4 & 34.0 & 24.5 & 41.8 & 38.6 \\
\hline
\end{tabular}

Este cambio de mando también se puede sustentar con los ajustes políticos internos y es que el enfoque de libre mercado y de libertad de los factores de producción, que había implementado Gran Bretaña durante más de un siglo, se rompía con la llegada de dos estructuras de poder diferentes a las acostumbradas y que ya no eran tan asequibles y manejables como había sucedido en otras épocas. En el caso de Brasil, la llegada de Getulio Vargas al poder en 1930, después de recibirlo por parte de los militares, y en Argentina, con el avance militar ante la dimisión 
de Yrigoyen en septiembre de 1930, permitieron romper un periodo que había consolidado a las economías, pero también el inconformismo por parte de algunos grupos poblaciones que no estaban de acuerdo con el manejo dado por la aristocracia terrateniente en Brasil y la sociedad pro-británica en Argentina.

\section{CONCLUSIONES}

Estados Unidos avanzaba en Latinoamérica a la sombra de sus intereses y proclamando cada vez más el uso de la Doctrina Monroe a finales del siglo XIX (Gilderhus, 2006, p. 10), al punto de involucrarse en situaciones como el diferendo limítrofe entre Venezuela y la Guyana Británica en 1895 y el conflicto cubano-español de 1898. Ese avance se limitaba a países cercanos o a países fácilmente influyentes o que no eran una pieza fundamental en el engranaje económico británico. Así mismo, fue el avance económico del occidente de los Estados Unidos, el Estado de California, el que en muchas ocasiones propuso la necesidad de vincular nuevos territorios para abastecer la alta demanda de recursos y productos finales.

Aunque Gran Bretaña mantenía una importancia económica hasta antes de la Segunda Guerra Mundial, ese avance de los Estados Unidos se da por dos razones: primero, por los espacios que Gran Bretaña permite y, en segundo lugar, por una política económica internacional definida y estructurada por el presidente Franklin D. Roosevelt hacia Latinoamérica como parte del New Deal y se desprendería en su política del «Buen Vecino». Este se sustentaba en lograr sortear los problemas que se presentaban a partir de la deficiencia agrícola y su influencia en la alimentación de la población de Estados Unidos, teniendo en cuenta la sobreproducción que se presentaba en Argentina y Brasil. Una política más amigable que la de su primo Teodoro Roosevelt, quien manejó una política más agresiva y menos comprometida con la igualdad de los Estados a principios del siglo XX, sustentado sobre el llamado Corolario Roosevelt. Sin embargo, para 1939, Gran Bretaña mantenía inversiones de 428 millones de libras para Argentina, y de 261 millones de libras esterlinas para Brasil (Rippy, 1948, p. 64), es decir, un crecimiento promedio anual desde 1930 de $2,10 \%$ y $8,08 \%$ respectivamente.

La transición en la inversión extranjera se consolidó por el deterioro británico generado por la Segunda Guerra Mundial, a pesar de la dificultades que vivió Gran Bretaña durante la Primera Guerra Mundial, donde pasó a ser deudor en los mercados internacionales, así como en sus mercados nacionales de deuda por un monto superior a los 7.000 millones de libras esterlinas (Balderston, 1989, p. 227), reduciendo ostensiblemente sus capacidades excedentarias que le permitían mantenerse como el mayor inversionista en los mercados argentino y brasilero. Sin embargo, esta situación no condujo a ser superado por Estados Unidos, sino hasta entrada la Segunda Guerra Mundial y a pesar de que fuera su mayor prestamista durante la Primera Guerra Mundial, con un monto superior a los 4.000 millones de dólares (Bullock, Williams y Tucker, 1919, p. 248). Ya Brasil y Argentina tenían una nueva opción de endeudamiento a través de la 
emisión de deuda (bonos) en el mercado estadounidense y la asesoría de los banqueros que se consolidaban en diferentes lugares de Latinoamérica, pero sería realmente la entrada de 1939 la que separaría la capacidad bancaria de Gran Bretaña y su interacción en Argentina y Brasil.

Estados Unidos avanzaba de forma importante en los mercados internacionales y superaba en diferentes actividades y países a los británicos, pero su capacidad de ingresar y reemplazarlos en Argentina y Brasil tomó mucho más tiempo, debido a que la importancia económica y la integración de los británicos en los procesos productivos habían generado lazos importantes con la estructura política, la aristocracia y la clase terrateniente. Así mismo, el abandono por parte de Gran Bretaña de su ideología liberal en las políticas comerciales y su concentración en la preferencia imperial afectaría considerablemente a Brasil, pero no tanto a Argentina, pues contaba con productos que no eran fácilmente reemplazables en sus dominios imperiales y que eran importantes en su mercado interno.

Un elemento adicional a tener en cuenta en esta transición fue el cambio político en Argentina y Brasil en 1930, el cual transformaría la forma de hacer economía, posiblemente por agotamiento del modelo exportador de los años anteriores o por una decisión política que restringía el avance económico a partir de los modelos liberales de comercio, en particular con el control de cambios impuesto por Brasil a principios de la década de 1930 y posteriormente por Gran Bretaña en 1939. Sin descartar que esto pudo ser el resultado de una acumulación de desequilibrios financieros que vivieron Argentina y Brasil entre 1890 y 1914 y, en especial, la devaluación de sus monedas en 1895, situación que detonaría el descontento de la población y de algunos grupos políticos años después. Sin embargo, hasta ese momento Argentina, con un próspero futuro, se veía con un importante rol en los asuntos políticos americanos e intercontinentales, al punto de poderse convertir en un contrapeso al avance de la influencia de los Estados Unidos (Díaz-Alejandro, 1970, p. 59). Pero los nuevos esquemas políticos internos los empezaron a alejar del reconocimiento económico en el sistema internacional y mucho más del reconocimiento político.

Finalmente, a pesar de ser tan importante para los mercados externos, la interacción entre Argentina y Brasil no fue lo suficientemente importante, a pesar de contar con mercados complementarios. Para el final del periodo de análisis, eran el $4.4 \%$ de las importaciones argentinas y el $3.8 \%$ de las importaciones brasileras unas tasas muy distantes de sus principales socios comerciales como Gran Bretaña, Alemania, Estados Unidos, Francia, Italia y Bélgica ${ }^{1}$. Sin embargo, aunque tenían diferencias en su procesos exportadores y, en definitiva, en su estructura económica, en los asuntos financieros contaron cada uno con el apoyo de una importante casa bancara: Baring, en Argentina, y Rothschild, en Brasil, y fueron las finanzas las que se convirtieron en el espacio más importante de la relación entre los dos países, no por una interacción directa, sino

3 Para un análisis más profundo, ver Díaz-Alejandro (1970) p. 20-21 
por la percepción del riesgo que se tenía de cada uno y la posibilidad de verse contagiado por alguna inestabilidad de cualquiera de los dos. Ejemplo de esto es la crisis de Baring, en Argentina, en 1890, y la implicación que tuvo para el precio de la deuda brasilera y la estabilidad de sus mercados financieros, no solamente por su cercanía sino por su inestabilidad financiera que se generaba por su alta exposición a los precios internacionales de los bienes básicos que exportaban y por ende en su estructura económica (Triner, 2001, p. 8). Esta situación pudo ser el elemento que permitiera avanzar hacia una consolidación económica regional, sin importar quién tuviera la hegemonía económica en la región.

\section{BIBLIOGRAFÍA}

- Abreu, M. de P. (2005) British business in Brazil: maturity and demise, 1850-1950. Rio de Janeiro: Catholic University of Rio de Janeiro.

- Albion, R. (1951) «Capital Movement and Transportation: British Shipping and Latin America, 18061914» The Journal of Economic History, Vol. 11, No. 4, pp. 361-374.

- Arrighi, G. (1999) El largo Siglo XX. Dinero y Poder en los orígenes de nuestra época. Madrid, edición en español por Ediciones Akal.

- Balderston, T. (1989) «War Finance and Inflation in Britain and Germany, 1914-1918» The Economic History Review, Vol. 42, No. 2, pp. 222-244.

- Beard, C. (1913) An economic interpretation of the Constitution of the United States. New York: Mcmillan Co.

- Bullock, C.; Williams, J.; Tucker, R. (1919) «The History of our Foreign Trade Balance During the Great War» The Review of Economics and Statistics, Vol. 1, No. 3, pp. 234-252.

- Bulmer Thomas, V. (2003) The economic history of Latin America since independence. New York: Cambridge University Press. Second Edition.

- Cain, P.J. and Hopkins, A.G. (1980) «The political economy of British expansion overseas, 1750-1914». The Economic History Review, Vol. 33, No. 4, pp. 463-490.

- Cain, P.J. and Hopkins, A.G. (1987) «Gentlemanly Capitalism and British Expansion Overseas II: New Imperialism, 1850-1945» The Economic History Review, Vol. 40, No. 1, pp. 1-26.

- Cardoso, E.; Brignoli, H. (1979) Historia económica de América Latina: Economías de exportación y desarrollo capitalista. Barcelona: Editorial Crítica.

- Cardoso, E.; Helwege, A. (1992) Latin America's economy: Diversity, Trends and conflicts. Cambridge: The MIT Press.

- Costigliola, F. (1977) «Anglo-American Financial Rivalry in the 1920s» The Journal of Economic History, Vol. 37, No. 4, pp. 911-934 
- Dean, W. (2000) La economía brasileña 1870-1930. En: Leslie Bethell (editor) Historia de América Latina, Vol. 10: América del Sur 1870-1930. Barcelona: Edición en español por Editorial Crítica. pp. 333-369.

- De Azevedo, Fernando (1944) A Cultura Brasileira. São Paulo: Companhia Editora Nacional.

- Díaz-Alejandro, C. (1970) Essays on the economic history of the Argentine Republic. New Haven: Yale University Press.

- Ferguson, N. (2004) Colossus. London: Allen Lane and Penguin Group.

- Ferns, H. S. (1950) «Investment and Trade between Britain and Argentina in the Nineteenth Century» The Economic History Review, Vol. 3, No. 2, pp. 203-218.

- Galiani, S.; Gerchunoff, P. (2003) «The labor market» En: Gerardo della Paolera y Alan Taylor (eds) A new economic history of Argentina. New York: Cambridge University Press. pp. 122-169.

- Gilderhus, M. (2006) «The Monroe Doctrine: Meanings and Implications» Presidential Studies Quarterly, Vol. 36, No. 1, pp. 5-16.

- Hobsbawn, E.J. (1987) The Age of Empire, 1875-1914. London: Weidenfeld \& Nicholson.

- Hobson, J.A. (1902) Imperialism: A study. London: George Allen \& Unwin.

- Jenks, L. (1944) «British Experience with Foreign Investments» The Journal of Economic History, Vol. 4, Supplement: The Tasks of Economic History, pp. 68-79.

- Kennedy, P. (1987) Auge y caída de las grandes potencias. Barcelona, edición en español por Plaza \& Janés editores.

- Kindersley, R. (1933) «British Overseas Investments in 1931» The Economic Journal, Vol. 43, No. 170, pp. 187-204.

- Lanciotti, N.; Lluch, A. (2009) «Foreign direct investment in Argentina: timing of entry and business activities of foreign companies, 1860-1950» Entreprises et Histoire, No. 54, pp. 37-66.

- Lebergott, S. (1980) «The Returns to U.S. Imperialism, 1890-1929» The Journal of Economic History, Vol. 40, No. 2, pp. 229-252.

- Marichal, C. (1984) «Los banqueros europeos y los empréstitos argentinos: rivalidad y colaboración: 1880-1890» Revista de Historia Económica, Vol. 2, No. 1, pp. 47-82.

- Marx, K. (1926) Capital: a critique of political economy, ed. Frederic Engels. Chicago: Charles Kerr.

- McGuaire, R. and Ohsfelt, R. (1986) «An economic model of voting behavior over specific issues at the constitutional convention of 1787» The Journal of economic history, Vol. 46, No.1, pp.79-111.

- McGuaire, R. and Ohsfelt, R. (1984) «Economic interests and the American constitution: A quantitative rehabilitation of Charles A. Beard» The Journal of economic history, Vol. 44, No.2, pp.509-519. 
- Mommsen, W.J. (1969) Das Zeitalter des Imperialismus. Frankfurt am Main: Fischer Bücherei K.G.

- Morse, R. (1984) «El desarrollo urbano de la Hispanoamérica colonial» En: Leslie Bethell (editor). Historia de América Latina, Vol. 3: América Latina Colonial: Economía. Barcelona: Edición en español por Editorial Crítica, 2000. pp. 15-48.

- Mulhall, M. (1896) Industries and Wealth of Nations. London: Longmans, Green \& Co.

- Mundlak, Y.; Regúnaga, M. (2003) «Argentine Agriculture» En: Gerardo della Paolera y Alan Taylor (eds) A new economic history of Argentina. New York: Cambridge University Press. pp. 233-260.

- Nicholson, J. S. (1910) «The economics of Imperialism» The economic journal, Vol. 20, No. 78, pp.155-171.

- Rippy, J.F. (1948) «British Investments in Latin America, 1939» The Journal of Political Economy, Vol. 56, No. 1, pp. 63-68.

- Rippy, J. F. (1949) «Investments of Citizens of the United States in Latin America» The Journal of Business of the University of Chicago, Vol. 22, No. 1, pp. 17-29.

- Salvatore, R.; Newland, C. (2003) «Between independence and the golden age: The early Argentine economy» En: Gerardo della Paolera y Alan Taylor (eds) A new economic history of Argentina. New York: Cambridge University Press. pp. 19-45.

- Skidmore, T. y Smith, P. (2001) Modern Latin America. New York: Oxford University Press.

- Stone, I. (1977) «British direct and portfolio investment in Latin America before 1914». The Journal of Economic History, Vol. 37, No. 3, pp. 690-722.

- Stone, I. (1999) The global export of capital of Great Britain, 1865-1914: A statistical survey. New York: McMillan Press.

- Street, J. (1982) «British Influence on Argentine Growth: The Dependency Controversy» Journal of Economic Issues, Vol. 16, No. 2, pp. 545-553.

- Summerhill, W. (1998) «Market Intervention in a Backward Economy: Railway Subsidy in Brazil, 18541913» The Economic History Review, Vol. 51, No. 3, pp. 542-568.

- Triner, G. (2001) International capital and the Brazilian encilhamento, 1889-1891. An early example of contagion among emerging capital markets? New Jersey: Rutgers University, Department of History.

- Winkler, M. (1929) Investments of U.S. Capital in Latin America. Boston: World Peace Foundation.

- Winslow, E.M. (1931) «Marxian, liberal and sociological theories of imperialism» The Journal of political economy, Vol. 39, No. 6, pp. 713-758

- Wright, W. (1967) «Foreign-owned railways in Argentina: A case study of economic nationalism» Business History Review, Vol. 41, No. 1, pp. 62-93.

- Zevin, R. (1972) «An interpretation of American imperialism» The Journal of economic history, Vol. 32, No.1, pp.316-360. 